\title{
Vestiges of the natural history of development: historical holdovers reveal the dynamic interaction between ontogeny and phylogeny
}

\author{
Alexander J Werth
}

\begin{abstract}
Vestigial features of humans and other organisms are well known and have long been used as key evidence for evolution. Such features include not only anatomical structures but also physiological processes, biochemical reactions, and even behaviors. In addition to remnants of evolutionary change, traces of developmental change likewise exist, and it is important to distinguish embryonic remains from true evolutionary vestiges because people confuse evolutionary and developmental changes. To avoid confusion, the term vestige should be reserved for true evolutionary holdovers. This paper presents examples of developmental remnants, which often involve circulatory and reproductive alterations, and discusses numerous other retained or reappearing historical holdovers in ways that reveal the unfolding dynamic interaction between genotype and phenotype. These holdovers are useful in differentiating and relating concepts of phylogeny and ontogeny as well as revealing benefits of historical reasoning in understanding patterns and processes of organismal change.
\end{abstract}

Keywords: Evolution; Development; Vestige; Holdover; Alteration; History; Function; Phylogeny; Teleonomy

\section{Introduction}

Life is a dynamic process, and organismal structures disclose the history of the two principal levels of biological change: evolutionary and developmental. Vestiges (from the Latin vestigium, for footprint) reveal traces of prior states. Like actual footprints, vestiges offer glimpses of what was once there but is no longer present. In biological terms, they reveal former evolutionary and developmental conditions, and in this way they offer valuable keys to unlock the past.

In standard textbook definitions vestiges are no longer functional. A broader definition might be applied that involves any trace of a former state, including nonfunctional features or those with greatly reduced function or a slightly or mostly different function as well as those that have not changed in function (if they ever had one). In addition, this expanded treatment might include not only vestiges in the evolutionary but also the developmental sense, which is seldom explored. Texts typically list numerous evolutionary vestiges of humans-the

Correspondence: awerth@hsc.edu

Department of Biology, Hampden-Sydney College, Hampden-Sydney, Virginia 23943, USA 'tail bone' (coccyx), vermiform appendix, 'goose bumps' and body hair, ear muscles, wisdom teeth-along with those of other animals, including dewclaws in dogs, pel$\mathrm{vic} / \mathrm{leg}$ bones in whales, and vestigial eyes of many cave animals, but the developmental dimension is typically ignored. Indeed, there are many biological phenomena which via retained or reappearing features yield historical information-traces of prior states of phylogeny and ontogeny-that can be used to classify taxa as well as to study evolution, development, and other aspects of organismal biology (e.g., anatomy, physiology). To avoid confusion, however, the term vestige should most properly be reserved for true traces or holdovers of evolution, not for remnants of embryonic processes.

Exploration of vestiges has several purposes: 1) to present a theme of historical thinking, explaining ways we reason from the past and why this is vital in biology; 2) to draw essential distinctions, often unappreciated, between evolution and development; and 3) to underscore the fundamental connections between ontogeny and phylogeny, shifting our traditional static view of anatomical structures and genes to a more accurate and fruitful outlook of species as perpetually unfolding 
developmental programs. This evo-devo perspective blurs boundaries between genotype and phenotype, shrinking the role of genes as inert blueprints and instead expanding their role as vectors in dynamic organisms-as developmental switches or triggers or context-dependent operational guides to phenotypic expression. This has profound consequences for historical reasoning about organismal form and function, which parallels historical themes concerning origins and outcomes of vestigial features and other rudimentary remnants and how they bear evidence about the past.

\section{Vestiges in historical context}

Progressive notions of natural philosophy and theology were simmering in Victorian England when, in 1844, the scientific establishment was rocked by the anonymous publication of Vestiges of the Natural History of Creation (Chambers 1844). This best-selling book presented, in a highly accessible format, then-radical ideas on cosmic and biological evolution. Not until forty years later, with the publication of the $12^{\text {th }}$ edition in 1884 , was the author revealed, posthumously, to be Scottish journalist Robert Chambers. Although Charles Darwin had already (by 1844) formulated, but not yet published, his mechanism of evolution by natural selection, Vestiges is credited-by scholars as well as Darwin himself-with broadly introducing the concept of transmutation of species to popular and scientific audiences, thus setting the stage for the 1859 publication of Darwin's landmark On the Origin of Species. It is difficult to estimate the impact that Vestiges had, for it was roundly criticized by scientists and hence is viewed today as little more than a historical footnote, but there is no doubt that Chambers' work shifted public opinion about the plausibility of evolution as well as philosophical materialism (Secord 2001). Although it sharpened rather than softened resistance to evolutionary ideas among scientists and clergy, Vestiges reached a huge audience and, one might argue, made evolution a mainstream concept.

Darwin invariably benefited not only from the trailblazing path that Chambers' book set, but also by lessons learned from the scathing reviews of this highly speculative volume. Already famously cautious, Darwin was now more insistent than ever on anticipating critics' charges and therefore amassing as many lines of evidence as possible to buttress his "one long argument" for the veracity of natural selection. Along with paleontological evidence from the fossil record and biogeographic evidence from species distributions, Darwin turned, naturally, to comparative anatomy, citing such well-known topics as homologous and analogous (convergent) features and similarities in skeletons and patterns of embryonic development. Darwin cited another prominent finding of comparative anatomy as an obvious line of evidence for evolution: vestigial features.
Anatomical vestiges had been described as far back as Aristotle (350 BC), in his History of Animals, and were widely discussed in the writings of Goethe, Buffon, Cuvier, Lamarck, and Geoffroy St. Hilaire (Muller 2002). In Origin of Species, Darwin (1859) explained that rudimentary (or "atrophied or aborted") vestiges could easily take on new, secondary functions; for his later Descent of Man (Darwin 1871) he compiled a list of vestigial features found in humans, including, along with those listed above, the semilunar fold of the corner of the eye or plica semilunaris, a remnant of the nictitating membrane. This list was greatly expanded by Robert Wiedersheim (1893) to over a hundred human vestiges.

Thanks in no small part to Darwin's efforts, vestiges of the human body are now familiar to a wide audience. However, vestigial features can be found in any species that has evolved-which is to say, all species. Furthermore, although we usually focus on 'useless' (apparently non-functional) structural features, other aspects of an organism's biology might be considered vestigial. These range from biochemical reactions or physiological properties, such as the mammalian dive reflex (present in humans but in much-reduced form relative to other mammals; Elsner and Gooden 1983), to biogeographic distributions of relict taxa, indicators of formerly larger populations. Straus et al. (2003) hypothesized that hiccups are a vestigial motor reflex pattern (of glottal closure during inhalation, so that the vocal folds slam shut) left over from early tetrapod vertebrates, specifically the tadpole larvae of amphibians. Tadpoles undergo a ventilatory transformation from external filamentous gills to pulmonary respiration, with a consequent need to close lungs to avoid ingesting water, which is diverted to gills instead (Shubin 2008). Even behaviors can be considered vestigial: witness the instinct in dogs to turn in a circle multiple times before lying down, presumably, though not assuredly, to tramp down a bed of grass (Irvine 2004). The palmar grasp reflex of human babies is thought to be a vestige from ancestral primates, where offspring needed a firm grasp of their mothers' fur as they were carried (Dewey 1935). Piloerection, leading to 'goose bumps' or 'goose pimples', can be considered a vestigial phenomenon in mostly hairless humans, and the arrector pili smooth muscles that pull on hair follicles and cause this autonomic reflex can be viewed as vestigial structures (Shubin 2008).

The flightless cormorant (Phalacrocorax harrisi), endemic to Fernandina and Isabela Islands of the Galápagos Archipelago, provides an excellent example of vestigial attributes. This bird possesses stumpy, stubby wings that are much too small to allow it to fly, unlike the 40 other species of cormorants found worldwide. The carina (keel) of its sternum is notably reduced, reflecting the muchdiminished pectoralis musculature of the breast, which is 
used in flying birds to produce the powered downstroke of flight. Nonetheless, as with all cormorant species, the flightless cormorant of Galápagos is an expert swimmer that tucks its wings close to its body and propels itself underwater with its strong webbed feet to catch the fish upon which it feeds. When it emerges from the sea and perches on rocky shores, it, like all cormorants, spreads its wings wide to dry them in the sunlight, since all birds in this family lack waterproof plumage. Research has shown that this basking behavior is not performed for thermoregulation or digestion but to dry and thus lighten the wings in preparation for flight (Sellers 1995). However, the flightless cormorant need not dry its wings because unlike its relatives and ancestors it cannot fly. Thus $P$. harrisi demonstrates not only conspicuous vestigial structures (its wings) but also a vestigial behavior (holding outstretched wings in the sun), neither of which is needed for its survival.

All of the examples cited in the previous paragraphswhether anatomical, physiological, or behavioral-have one thing in common: they are vestiges of evolution, artifacts of the progressive change that occurred over generations via natural selection, and which Darwin referred to as descent with modification. Often, features of organisms (structural and otherwise) are not modified during the descent from parent to offspring, from ancestor to descendant. These features can be retained for remarkably long stretches of time, especially when they are not subject to strong selection and there is little obvious 'cost' to maintain them. The vestigial pelvic and hind limb bones of whales, which have not borne functional legs for 40 million years, are a prime example of vestigial retention (although these bones still serve as attachment sites for genital and abdominal musculature, so the cost of their loss might be significant). Note that today's common usage is a narrower sense of the word 'vestige' than was employed by Chambers, whose Vestiges of the Natural History of Creation (Chambers 1844) referred not only to what would today be considered non-functional evolutionary leftovers, but to any traces that reveal life's past.

As commonly applied today (contra Chambers' wider usage), the term vestige refers to something that has lost a former function during evolutionary change, such as our appendix, tail bone, and goose bumps, or the rudimentary pelvic bones of cetaceans and some large snakes. Darwin claimed these vestiges offer compelling evidence for evolutionary change because even though the function has been lost or altered, the structure, behavior (e.g., cormorant wing drying), or physiological/ biochemical process remains. Scadding (1981) did not deny the factual basis of evolution but nonetheless argued, contrary to Darwin, that vestigial organs provide no special evidence for evolution because "it is difficult, if not impossible, to unambiguously identify organs totally lacking in function."

However, evolution is not the only widespread change that is manifested in organisms. Numerous embryonic rudiments may be retained as recognizable remnants in later developmental stages of animals and plants, including adults. Ontogenetic changes (i.e., developmental modifications occurring during an organism's lifespan) can be more drastic than phylogenetic changes, perhaps due to the speed and scope with which development advances, and similarly reflect major biological processes. Nipples in male mammals provide a classic example (to be explained in detail). Other clear developmental 'vestiges' come from the circulatory system of eutherian (placental) mammals, which undergo rapid and radical changes from fetal to newborn circulation, and from vertebrate urogenital (excretory and reproductive) systems, which in both males and females share many incipient structures that quickly shift function during sexual differentiation. Detailed examples of various developmental relics follow.

The topic of developmental 'vestiges' and their proper distinction from true (evolutionary) vestiges provides an opportune occasion for biologists to focus more clearly on the fundamental differences between processes of organismal change, which often bedevil students who lack a clear grasp of evolutionary patterns and processes. We must be especially careful not to confuse ontogenetic traces of development (like male nipples), whose significance is often overlooked, with phylogenetic vestiges of evolution (like our appendix). This paper presents and distinguishes examples of variously retained features (Table 1), particularly in the human body, as it discusses their importance and utility in relating evolution and development. Given the myriad challenges of evolutionary education and the potential importance of vestiges in explaining evolution, reserving the term vestige solely for holdovers of evolution is recommended to avoid unnecessary confusion.

\section{Embryonic remnants of mammalian circulation}

As anatomists know, some of the best examples of nonfunctional developmental 'vestiges' involve mammalian circulatory changes. These are detours or shunts (pulmonary to systemic, or 'right to left') occurring in the shift from fetal to neonatal mammalian circulation. Consider that lungs are not used for pulmonary ventilation by any mammals in utero, but they must be fully developed so that they can function effectively and independently to oxygenate the blood of a newborn infant after oxygen is no longer supplied by the placenta. Therefore the blood vessels that will function outside the womb must be constructed before birth, even though they do not function until after birth, when the fetal vasculature 
Table 1 Examples of historical holdovers, phylogenetic and ontogenetic, revealing traces of prior conditions

Original function altered or absent
(=non-functional)

Function lost or shifted, yet compound clues reveal joint evo-devo history within lineage

May be altered or non-functional; development in divergent lineages reveals clues to history/homology (in common origins \& developmental processes)

\author{
Developmental \\ Circulatory shunts including fossa ovalis \& \\ ligamentum arteriosum; male nipples; \\ inguinal canal \& looped vas deferens from \\ descent of testes \\ Cranial sutures \& epiphyseal joints; umbilicus \\ (navel) \& other scars
}

dewclaw; cave animal eyes; coccyx; vermiform appendix; piloerection

Primate fingernails \& stereoscopic vision as synapomorphies (shared, derived characters); cephalization with terminal rather than central head

Atavisms: Sudden reversion to retention of tail in humans or of limbs in snakes or cetaceans; bird teeth; Exaptations: fish lungs before swim bladders; feathers for insulation before flight

Homologies: Pharyngeal glands (e.g., tonsils) \& chordate gill arches; male \& female genitalia

Phylogenetic (not merely phyletic) processes: mammalian ear ossicles as derived reptilian jaw bones; mammary glands as derivative sweat glands; perhaps sexual dimorphism in size and structures as conserved features shifts immediately to a new pattern. That this change occurs at all is a marvelous feat of embryology; that it leaves very few (but notable) artifacts of the original blood supply network is a wonder of nature. Such circulatory shunts, listing the original fetal and ensuing neonatal 'vestigial' vessels or structures, include:

\section{Foramen ovale $\rightarrow$ fossa ovalis}

This bypass, essentially an oval-shaped hole in the septum dividing the right and left atria, normally closes when the pressure head in the systemic (left) half of the mammalian circulation exceeds that of the pulmonary division, pressing a flap of tissue to close the hole. The tissues soon fuse and all that remains is an oval-shaped depression. However, up to $30 \%$ of adult humans retain a patent foramen ovale (PFO, or atrial septal defect; Hagen et al. 1984), which compromises cardiopulmonary function because deoxygenated blood returning from the body can, as in the fetal pathway, bypass the nowfunctional lungs and be sent to the left side of the heart and on via the aorta to other organs and tissues of the body.

As with the other fetal circulatory shunts described here, there is a difference between functional closure, which typically occurs within minutes after birth, and structural closure, which usually takes days or weeks. It has been speculated that levels of circulating hormones, particularly prostaglandins, may regulate shunt closure and timing (Fugelseth et al. 1998). Babies born prematurely often have difficulty with the transition to normal postnatal circulation because they retain fetal circulatory patterns due to delayed shunt closure (Evans and Iyer 1994).

\section{Ductus arteriosus $\rightarrow$ ligamentum arteriosum}

Even if fetal blood from the right atrium escapes passage through the foramen ovale into the left atrium and travels, as in postnatal mammals, to the right ventricle, it cannot go to the lungs because they are not yet inflated. The ductus arteriosus (AKA ductus Botalli), a bypass from the pulmonary trunk to the aorta (i.e., the fourth to the sixth aortic arches), normally withers in the days following birth to become a shriveled band of tissue, the ligamentum arteriosum. This remnant, which connects the pulmonary trunk and aorta, can be found in all mammals.

\section{Ductus venosus $\rightarrow$ ligamentum venosum}

The ductus venosus of fetal mammals shunts oxygenated blood returning from the placenta via the umbilical vein away from the liver and instead directly into the inferior vena cava. This oxygenated blood serves the developing brain and other organs via the systemic circulation. The ductus venosus closes shortly after birth (functionally, with full structural closure occurring days later); its fibrous remnant is known as the ligamentum venosum. This is often continuous with the round ligament of the liver, also known as the ligamentum teres hepatis, described below.

\section{Umbilical vein $\rightarrow$ ligamentum teres hepatis}

As noted, the umbilical vein carries oxygenated blood from the placenta. It is open at birth but closes within a week. During the time it is open it can be catheterized, allowing for delivery of drugs or for blood transfusion. Within days after closure the umbilical vein is mostly obliterated except for a fibrous portion on the abdominal wall that remains as the ligamentum teres hepatis. Curiously, this may reopen in adults with extreme hypertension (although this is debatable; Lafortune et al. 1985), especially near the liver, as can occur when hepatic vessels are obstructed by scar tissue from cirrhosis. The distended, engorged paraumbilical veins are visible on the abdomen, where they resemble the mythical 
snakes of Medusa's head, leading to the medical name caput medusae.

\section{Umbilical arteries $\rightarrow$ umbilical ligaments, and the} superior vesicular artery supplying the urinary bladder Umbilical arteries carry deoxygenated fetal blood back to the placenta, and as such are unnecessary after birth. They usually close before the umbilical veins, allowing all fetal blood to drain into the newborn's circulation. Umbilical arteries give way to a functional section of the internal iliac arteries and superior vesicular artery that delivers blood to the dorsal portion of the urinary bladder, as well as a non-functional, obliterated portion (which led to the umbilical cord) that becomes the medial umbilical ligament, not to be confused with the median umbilical ligament, a remnant of the urinary urachus, itself an embryonic remnant of the allantois.

\section{Ductus caroticus (as persistent third aortic arch)}

The carotid duct or ductus caroticus remains in some postnatal vertebrates (lungfishes and some amphibians and reptiles) as a remnant of the original embryonic connection between the third and fourth aortic arches.

Information about these circulatory 'vestiges' can be found in basic embryology or comparative anatomy texts.

\section{Embryonic remnants of the mammalian urogenital system} Aside from these circulatory artifacts, the best examples of non-functional embryonic 'vestiges' come from the developing urogenital system. Not only do excretory (urinary) and reproductive (genital) systems share many developing tubes but there is also shared 'plumbing' between developing males and females. This occurs because although the sex of a developing embryo is determined at conception (in humans, as in other mammals, due to the presence of an $\mathrm{X}$ or $\mathrm{Y}$ chromosome in the sperm), this sex does not become phenotypically manifested until much later in development. In early development, the embryo develops along 'indifferent' lines as a sort of unisex model that later differentiates into a male or female phenotype. Often, leftovers of earlier stages can be seen in adults. Many of these embryonic 'vestiges' cannot be seen externally; others, like nipples on the chest, are readily visible.

Homologies of shared urogenital structures occur because sexual development typically occurs along a default female track that, in the absence of any outside influence-namely the testis determining factor (TDF) produced by the sex-determining region of the $\mathrm{Y}$ chromosome (SRY)-turns the indifferent stage into a female embryo. Males often retain relics of their 'female' (technically, indifferent) origins, just as females may retain remnants of structures that arise in early embryos and later become male features. Thus many nonfunctional developmental 'vestiges' relate to sex differences and sexual development.

\section{Wolffian \& Mullerian ducts}

The mesonephric (AKA archinephric or Wolffian) and paramesonephric (AKA Mullerian) ducts of embryogenesis begin developing in both male and female vertebrates, including humans. In males, the Wolffian duct becomes the efferent or deferent duct (including the epididymis, vas deferens, and seminal vesicle) that stores and transports sperm and seminal fluids. In females, the Wolffian duct degenerates and remains solely as a withered rudiment. In females, the Mullerian duct becomes the oviduct, including the Fallopian tubes, uterus, cervix, and upper portion of the vagina, whereas in males the Mullerian duct regresses completely or is seen as a small remnant. Many exceptions can found among vertebrate clades in the fate of both Wolffian and Mullerian ducts, particularly teleost fishes, which have novel testicular and ovarian ducts-the story is much abbreviated here for simplicity-but the basic account of one tubule being used as a functional duct in males and the other in females holds true; retention in other sexes occurs solely as non-functional residues. Sections of the Wolffian (archinephric) duct normally remain in human females. These include the more anterior epoophoron and the paroophoron (homologous to the male epididymis and paradidymis, respectively) next to the ovary, and the more posterior Gartner's ducts next to the vagina.

\section{Inguinal canal}

The Wolffian duct develops in males into the vas deferens. In mammals testes normally descend permanently or temporarily into a scrotal sac for better spermatogenesis, the cooler temperatures of the scrotum allowing for improved production of viable sperm. [Is this low temperature requirement itself a sort of pre-endothermic vestige?] The vas deferens thus must traverse the abdominal wall in males, and it does so at the inguinal canal. This weak spot in the abdominal wall is the cause of inguinal hernias in men. The vas deferens (efferent duct) takes a long, looping path over the ureter, a developmental holdover of the original descent of the testes into the scrotal pouch. The odd looping pathway the ureter takes is reminiscent of the recurrent laryngeal nerve, a branch of the vagus nerve (cranial nerve $\mathrm{X}$ ), whose unusual circuitous detour on the left side, as it loops under the aorta, was noted in giraffes by anatomist Richard Owen (1841).

\section{Primary and secondary sex cords in indifferent gonads}

Developing 'sex cords' also arise prior to sexual differentiation. These are the first and most important difference in the indifferent gonad. Primary sex cords of the 
gonad's medullary region become Sertoli cells of the seminiferous tubules that comprise the majority of the testes; later rete cords (AKA cords of urogenital union) connect these to the efferent duct (essentially, the vas deferens). In females, the primary medullary sex cords degenerate, where they may remain as ontogenetic vestiges, and instead secondary sex cords invade the cortex of the gonad and become ovarian follicles.

\section{Male nipples}

In all mammals, nipples develop along the milk line of the mammary ridge. Humans, like other primates, develop pectoral breasts along the anterior (=superior, in humans) portion of this milk line. Other mammals, including manatees, develop mammary glands that are even further anterior in the axilla ('armpit'). Cats, dogs, and other familiar pet or barnyard mammals have abdominal mammaries that develop much more posteriorly (inferiorly) than in humans. Ungulates have inguinal mammary glands; rodents and pigs develop them along the entire trunk, including both the thorax and abdomen.

In humans the milk lines or mammary ridges develop around the sixth week, and although two nipples usually form, extra (supernumerary) nipples occur not infrequently in males and females. But why should male mammals have nipples at all? Interestingly, Darwin (1871) perpetuated the myth that male nipples are true evolutionary vestiges that stem from lactation in male as well as female ancestral mammals. This mistaken notion was based on rumors that circulated with the first, largely erroneous European scientific descriptions of the duck-billed platypus. We now know male monotremes do not produce milk, so male nipples are not in any way an evolutionary holdover. They are, however, a developmental holdover from the early, indifferent stage of embryonic development, when the milk line arises but before the embryo has developed along the default female track or divergent male pathway. After this switch has occurred, nipples are already present and are not resorbed. Evidently, there is little or no cost to retaining nipples and associated mammary tissue in males, aside, perhaps, from a slight risk of breast cancer. If there was a true cost to retention of male nipples or selection pressure against their presence, they would likely not be retained. Like the urogenital ducts described above, male nipples are default structures formed earlier in development than the differentiation between males and females.

\section{Other holdovers of evolution and development}

Whereas true vestiges, whether anatomical, behavioral, or physiological, reveal information about evolutionary history, the circulatory and urogenital embryonic 'vestiges' described above yield clues to developmental history. However, even if one reserves the term vestige solely for leftovers of evolutionary change, as recommended here, it is interesting and useful to consider the broad sense of 'vestiges' as originally intended by Chambers. Just as footprints reveal traces of a person or animal that is no longer present, numerous features of organisms reveal historical information about phylogeny and ontogeny.

In many cases there are features of organisms that may (unlike vestiges) retain an original function but nonetheless reveal glimpses of history via comparative cladistic analysis of a species and its lineage (Table 1). Again these can be divided into traces from the past that indicate prior states of evolution or development. On the evolutionary side, these include shared, derived characters (synapomorphies) like the stereoscopic (binocular) vision and fingernails of primates, which yield information about the ancestry and evolutionary relationships of this mammalian order when compared to other mammals. Bilaterally symmetric embryos of echinoderms, which as adults display pentamerous radial symmetry, likewise are relics that disclose secrets of echinoderm origins. Even the possession of a head region at one end (rather than in the center) of cephalized animals is a form of historical remain: still obviously functional yet a reminder of the past, when heads first arose. In this sense they are indeed faint footprints, but not true vestiges in the proper evolutionary sense.

Other functional remains indicate developmental history. Examples include cranial and other bony sutures that reveal formerly distinct ossification centers. During formation of endochondral (cartilage replacement) long bones, a growth zone forms between the bony shaft (diaphysis) and end plate (epiphysis). These elements eventually fuse when growth ends, leaving a tell-tale epiphyseal line where elements were formerly separated. This too is an artifact of ontogeny. Locations where bone has been broken or seriously bruised or otherwise injured likewise disclose marks of Haversian ossification where the bony tissue has 'reknit' itself, although this is not a standard process of development and is not found in all long bones or all animals that possess them. [It is often easy to distinguish remnants of development from remnants of healing or routine maintenance, such as primary versus secondary osteons.] Perhaps the most conspicuous ontogenetic leftover is found on the abdomen of all placental mammals: the umbilicus (navel or "belly button'). Strictly speaking this is a scar: although the umbilical cord has a function, the umbilicus itself never had one, making this a nonfunctional embryonic holdover, unlike the formerly functional circulatory and urogenital remains described earlier.

Sometimes a feature's function (if it ever had one) can be lost or shifted, but compound clues together reveal the intertwined relationship between a lineage's phylogeny 
and ontogeny. For example, the vestigial coccyx, a remnant of a now-missing tail, shows how developmental remnants reflect evolutionary history, revealing the complex association that leads to such structures being expressed (or not), which is itself an informative aspect of organismal history. To take another example of compound historical clues, apoptosis (programmed cell death) typically transforms a paddle-like vertebrate limb bud into a hand or foot with distinct, discrete digits. The webbing between digits of a foot, as in waterfowl like the flightless cormorant, generally reflects the lack of such cell death and thus reveals the largely unaltered embryonic limb bud as a sort of simple ontogenetic artifact, yet one that is still obviously functional as a webbed foot and that bears too on the evolution of the taxon when viewed in comparison with related taxa (e. g., a duck's foot vs. a chicken's). Consider too that these traits can apparently be shifted on and off-i.e., alternately expressed or lost in phenotype-via regulatory gene activity.

When a formerly lost trait re-emerges in 'throwback' form, the resulting atavism (from the Latin atavus for ancestor, or literally great-great-great grandfather) is a kind of re-appearing artifact. Retained tails in humans, or external hindlimbs in cetaceans and snakes-lost from ancestors but present again-are other telltale clues to organismal history, both phylogenetic and ontogenetic, as are the re-emergent "hen's teeth and horse's toes" that Gould made famous in his book of the same name (1983). What atavisms tell us is that what evolution has put away, development can quickly restore. Switches that turn off gene expression can turn back on, and hence these evolutionary remnants reveal the dynamic interplay between "ontogeny and phylogeny" that Gould expounded on (1977).

In many cases it is not easy to disentangle the evolutionary and developmental processes that interact to produce wholesale phenotypic alteration. Consider the six basic 'diagnostic' features of the Phylum Chordata, found in all chordates (and only chordates) at some point in their life cycle: the notochord; single, dorsal, hollow neural tube; myomeres (segmental muscle units); postanal tail; pharyngeal slits; and endostyle. The arches surrounding pharyngeal slits develop, and evolved, into the mandible, hyoid, and other arches of the vertebrate splanchnocranium, particularly the branchial skeleton or 'basket' surrounding the gills of fishes. The slits themselves are transformed during development, as they have been transformed during evolution, into portions of the inner ear, tonsils, and thymus, all with distinct innervation by various cranial nerves (Sadler 2009). In humans, the first pouch develops into the pharyngotympanic (Eustachian) tube; the second pouch contributes to the palatine tonsils and middle ear (supplied by the facial nerve); the third into the inferior parathyroid glands and cells of the thymus (supplied by the glossopharyngeal nerve); the fourth into laryngeal musculature and cartilage, as well as the superior parathyroid glands and calcitonin-producing ultimobranchial bodies, which form the parafollicular portion of the thyroid gland; the fifth into part of the thyroid; and the sixth pouch into musculature and cartilage of the larynx. In short, it is not possible to disconnect ontogenetic from phylogenetic remnants in this instance. Homologies of these jointly conserved evolutionary-developmental structures constitute another type of historical residues.

Similarly, the endostyle-another of the six diagnostic chordate features-is known (from its metabolic and iodine-concentrating activities) to be homologous to the thyroid gland. This represents another relic of shared ontogenetic and phylogenetic transformations. Likewise all chordates possess, again at some stage of the life cycle, a postanal tail. Because the tail is retained in many 'adult' (i.e., sexually mature) chordates-and in nearly all adult vertebrates, with the major exception of apes and frogs-this can often be viewed as a true evolutionary vestige when the tail is partly or wholly non-functional in adults. Remains of the notochord are retained as the gel-like nucleus pulposus at the center of intervertebral discs. It is difficult if not impossible to discern these transformations as remnants of solely evolutionary or developmental alteration-plainly, these changes are intertwined-but it is abundantly clear that the structures that remain are mere shadows of their former ontogenetic and phylogenetic states, and thus guides to organismal history. With regard to the urogenital holdovers outlined earlier, many well-known homologies of male and female genital structures-for example, the male glans penis and female clitoris; the scrotum and labia majora-are evo-devo traces of shared early origins. The gubernaculum testis, a narrow band of connective tissue that 'pulls' the descending testes down into the scrotum, is homologous to the round ligament that suspends the ovary.

Ernst Haeckel's so-called 'Biogenetic Law' ('ontogeny recapitulates phylogeny') has long been discredited, and controversy surrounds Haeckel's illustrated embryos with which he argued his recapitulation hypothesis, but there is no doubt that early embryos resemble each other more closely than do late-stage embryos (von Baer's Law). This is not surprising given the centrality of mosaicism in evolutionary and developmental change, with a basic framework of ancestral, plesiomorphic features that is later supplanted or overlain by derived apomorphies. Nonetheless, in development as in evolution, the basic outline is not always erased, and tantalizing residues or traces of earlier forms often remain visible even in later stages of evolution and development. 
Whereas the compound atavistic and homologous clues can be seen as revealing historical changes within a single evolutionary lineage, others are best viewed through the prism of divergent lineages. The latter kind of relationship-not merely phyletic but phylogenetic (literally, referring to the origin of a new phylum or major taxon)-reveals a history that can be concurrently approached from two directions, as each clade relates to the other and as both depart from their common ancestor, best studied as corresponding divergences of developmental programs.

One of the best examples of such a major remnant of evolutionary and developmental history involves the mammalian middle ear ossicles (the malleus, incus, and stapes bones), all of which are derived from jaw bones of ancestral reptiles but which now play a key role in hearing by amplifying sounds. The joint evo-devo changes of these structures in mammals (where they are still functional, but with a new function), as well as in extant reptiles that have also evolved from the common ancestor with mammals, provide much evidence as to joint ontogenetic and phylogenetic transformation. A similar example comes from the origin of mammary glands as derived sweat glands. Even sexual dimorphism in body form and size can, in many lineages, represent retention of former evolutionary and developmental conditions. When seen from the perspective of closely related lineages (e.g., humans and apes) and their extinct common ancestors, these features tell us not only about extant taxa. They can also reveal important lessons about their history.

To most minds evolution is a steady progression of change, but what ultimately marks vestiges and other 'holdover' phenomena is a distinct lack of change. George Williams (1997) pointed out that adaptationist stories "are not about evolution so much as about its absence" in the sense that adaptations represent static retention of features because stabilizing selection culls less optimal forms. Thus adaptations too reveal important lessons about the past, and this is particularly true when environmental changes render an adaptation apparently useless. A good example is the large, hard-shelled, gourd-type fruit of the calabash (Crescentia) tree, which has been posited as an 'anachronistic' adaptation for seed dispersal by gomphotheres, large, elephant-like mammals that went extinct over 10,000 years ago (Janzen and Martin 1982). With exaptations ('pre-adaptations') the function changes over time, yielding other historical information. As with vestiges, an exaptation can be a structure but it can also be a behavior or process. Examples of classical structural exaptations include the lungs of early fishes, which in most osteichthyan clades evolved into swim bladders for buoyancy control, and avian feathers, which initially arose as thermoregulatory (insulating) structures but now also serve courtship (display) and locomotor (flight) functions. Licking of human faces by dogs might be seen as a behavioral exaptation, which now aids in bonding and socialization but which has been hypothesized to have initially evolved in ancestral wolves as a submissive behavior that prompted dominant wolves to regurgitate food (Jacob 1977). This is an evolutionary change but also a sort of paedomorphic change, in that the licking occurred in wolf pups but is now retained in adult dogs. Paedomorphosis, the retention of 'child-like' larval or juvenile forms (like the external filamentous gills of aquatic salamanders), is yet another way in which organismal features are retained rather than changed, and another way in which the interactions of phylogeny and ontogeny are reflected in their mutual history.

\section{On the role of vestiges and other historical clues in relating/differentiating ontogeny and phylogeny Recognizing crucial (but slippery) distinctions between evolution \& development}

Vestiges are not mere curiosities or footnotes. As the above examples show, they, along with many other historical holdovers, reveal the dynamic interplay between evolution and development. More than that, such remnants help us to see the distinction between these related and highly similar yet discrete processes. This often befuddles laypeople, who use the terms 'evolve' and 'develop' interchangeably. But can biologists themselves clearly articulate the differences? This is not so easy because several disparate criteria can be used to distinguish evolution from development (Table 2).

People frequently refer to the evolution of Earth or the universe in describing eons-long changes that have occurred to these and other heavenly bodies. This is an accepted convention, even within science, but in a crucial technical sense it may be incorrect to do so, for these changes reflect alterations that occur over the time scale of a single entity, and as such can be seen as developmental rather than evolutionary processes (provided there have not been successive 'generations' of universes, or 'multiverses', which we cannot rule out). Earth has changed remarkably over its long history, but it is still the same planet that formed 4.5 billion years ago. Earth as we know it today is not a descendant of an earlier Earth which is no longer present. Strictly speaking, there have not been multiple generations of Earth. Yes, it is always good to introduce the word 'evolution' to conversations about natural phenomena, but in a formal way, changes in the history of our (or another) planet or other heavenly body reflect developmental modifications of the same entity, rather than a newer offspring. By the same token, biologists must be careful not to speak of the development (rather than evolution) of horse or fern lineages. 
Table 2 Comparison/contrast of the two major dynamic processes of biological change

\begin{tabular}{|c|c|c|}
\hline & Evolution & Development \\
\hline Basic definition & $\begin{array}{l}\text { Genomic (inherited) changes in populations over } \\
\text { successive generations }\end{array}$ & Changes within the life history of an individual organism \\
\hline Time frame/scale & Change occurs between generations of related entities & Change occurs within lifespan (birth to death) of single entity \\
\hline Source of change & $\begin{array}{l}\text { Inherited changes due to random mutation and } \\
\text { directed selection }\end{array}$ & $\begin{array}{l}\text { Preprogrammed changes occur via unfolding/expression of } \\
\text { internal plan }\end{array}$ \\
\hline Programmed? & $\begin{array}{l}\text { Teleonomic (apparently goal-directed but not teleologic) } \\
\text { yet not programmed }\end{array}$ & $\begin{array}{l}\text { Teleonomic \& programmatic, with changes guided by and based } \\
\text { on program of coded information }\end{array}$ \\
\hline Adaptive? & $\begin{array}{l}\text { Generational changes of organisms adapt to changes } \\
\text { in environment }\end{array}$ & $\begin{array}{l}\text { Changes within organisms generally do not relate to adaptation } \\
\text { or respond to environmental shifts }\end{array}$ \\
\hline
\end{tabular}

This may seem to be a minor technical point, but for many people, particularly those just learning concepts of evolutionary biology, it is a fundamental point too often missed. Proper terminology is important in all situations. When distinguishing wholly separate yet confusingly similar phenomena it is essential. To the untrained mind, it is easy to conflate evolution and development as related aspects of the same process of long-term change.

Perhaps paradoxically, this point is more important than ever now that the word 'evolution' has entered the public consciousness and lexicon as a mainstream notion. Even people who lack a firm grasp of biological concepts refer to 'evolution' in everyday language. We speak of the evolution of automobiles (e.g., Chevrolet Corvettes or Volkswagen 'Beetles') over different model years, with distinct changes occurring to fenders, bumpers, and headlights, not to mention engines and myriad internal features. In the same way, we talk about the evolution of musical groups (e.g., the Rolling Stones or Grateful Dead) as various band members leave and are replaced. In both cases, 'evolution' is used in a way that is consistent with proper scientific usage: what remains of the car or band is a 'descendant' of a related though somewhat different 'ancestral' forerunner that preceded it. Likewise, we could at the same time consider developmental changes that occur over the lifetime of a single entity, organic or inorganic (e.g., Mick Jagger or a '64 Corvette), as it undergoes age-related changes in its life history passage. The point is that we must take care to avoid confusing or conflating these disparate types of change. Evolution and development are not the same.

However, in another fundamental sense the unfolding history of our planet and universe are indeed best described as evolution rather than as development, in that these events do not involve the following of instructions encoded in a program, as occurs in organismal development. This standard view of development as a teleonomic (seemingly goal-directed; Mayr 1974) process stands in stark contrast to the accepted view of evolution as non-programmatic, with no obvious end in sight. Whereas we can characterize typical developmental stages from beginning to end, and clearly recognize when this process goes awry, we have no way of knowing what the future of evolution can bring because we cannot be sure what new variation will arise and what future environmental conditions will exist to exert selective pressures on that variation.

This reveals another major distinction between evolution and development (Table 2). We recognize that although evolving lineages are not fulfilling a preordained plan, they do adapt or respond to environmental conditions. In contrast, we should be wary of thinking of a changing universe (or other abiotic entity) as adapting. Perhaps the key distinction between evolution and development has less to do with time scales, discrete generations, or adaptation than with conventions of language, which is notoriously imprecise. The 'history' of our individual immunities to specific antigens can be seen as both developmental and evolutionary when we consider that it involves clonal selection of antibodies.

\section{Recognizing crucial relations and interactions between evolution \& development}

The 'vestigial' features of development outlined in this paper stand in contrast to the far-more frequently cited vestiges of evolution. However, it is important to note that although vestiges are useful in explicating differences between evolution and development, they help to explain the synergistic interrelationship both processes share in determining organismal form. Vestigial attributes such as pharyngeal pouches reflect the intertwined nature of phylogenetic and ontogenetic transformations that are impossible to disentangle. This 'two-way' relationship has attracted widespread attention in recent decades with the ascension of evolutionary-developmental biology ('evo-devo') as a leading field of biological investigation. Researchers continue to make valuable strides in comprehending the ways that molecular mechanisms of genes are altered and selected during evolutionary change, and in our understanding of the ways that genes in turn affect phenotype and thus evolutionary patterns. Still, an evo-devo outlook downplays the preprogrammed view of development given that various 
potential ontogenetic trajectories can be selected by prevailing environmental circumstances, making development more fluid than encoded. Given enough royal jelly, any bee larva can become a queen. Sex is often determined by chromosomes, but also by ambient temperature, age, pheromone levels, or demographics.

That the vestigial remnants of true evolutionary changes provide key evidence for evolutionary changes cannot be denied, nor can the dynamic relation between phylogeny and ontogeny. In the famous words of Leigh Van Valen (1973), "Evolution is the control of development by ecology" (except in clades where there is no clear developmental sequence). No aspect of an organism is static, and in studying the history of life we must be mindful of the perpetually unfolding interplay between gene, environment, and anatomy, both dynamically mutating and dynamically selected. Numerous fascinating studies have revealed how minor genetic and molecular tweaks have major ramifications on organismal phenotype. For example, Osterauer et al. (2010) found that exposure to platinum causes young snails to develop into shell-less, slug-like gastropod molluscs. Freitas et al. (2012) showed that overexpression of the hox13a gene in zebrafish (Danio rerio) causes fin reduction and proliferation of distal cartilaginous tissue similar to that seen in the digital arch of tetrapod limbs; further, the same gene promoter (a 5' Hoxd enhancer $\mathrm{CsC}$ ) is involved in turning embryonic limb buds into fish fins as well as tetrapod hands. Such studies show that minor molecular changes can provide major anatomical shifts, all of which might prove pivotal in evolution. No living birds have teeth, but we can tweak regulatory genes of embryonic chicks to 'switch on' stillpresent structural genes that encode for teeth. Still, we can only speculate as to the evolutionary significance of 'internal' molecular mechanisms, which are often silent or neutral, whereas we can see, directly and immediately, the profound consequences of these shifts (on snail shells, fish limbs, hen's teeth, and so on) in external phenotypes.

Just as illnesses, injuries, and other accidents of ontogeny often leave remains in the form of scars where tissues have incompletely healed from damage, chance events of phylogeny can likewise leave 'vestiges' in the form of molecules and nucleic acid sequences that are non-functional (as might apply to 'junk DNA'). In this way, both evolution and development might be said to leave vestigial remains not only in the phenotype we see, but also in the genotypic basis that helps to determine phenotypic expression (provided the genotypic changes are to the germ line, and thus heritable). Both kinds of vestiges result from solitary events in individual organisms. A crucial difference, however, is that whereas scars and other traces of injury (e.g., from regenerated limbs) remain a part of that organism, they are not passed along to the next generation, and in that essential sense they do not conform to a fundamental tenet of vestigiality as commonly understood. Vestigial features are properties of species-they apply to all members of a species (Knobloch 1951), and are inherited by offspring from parents-and thus they can evolve, or rather persist, as generally happens with a vestigial structure, process, or behavior. In the truest (most literal) sense, then, vestigial features cannot be defined as remnants or residues of events that occur to individual organisms unless they alter the underlying DNA that is expressed in the phenotypic change, whether structural or behavioral. These underlying and inherited genetic instructions are essential for vestigiality. In the end, both phylogenetic vestiges and ontogenetic 'vestiges' evolve. Although there are central distinctions between evolution and development, ultimately even development-as a whole, and including every developmental process-evolves.

\section{Competing interests}

The author declares that he has no competing interests.

\section{Acknowledgments}

Two anonymous reviewers supplied many helpful suggestions that greatly improved the writing and organization of this paper. I am also grateful to Douglas Allchin, Bill Shear, and Russ Stullken for valuable suggestions and ideas.

Received: 7 February 2014 Accepted: 15 April 2014

Published online: 03 May 2014

\section{References}

Aristotle (350 BC). D'Arcy Wentworth Thompson 1907. The History of Animals, trans. London: John Bell.

Chambers, R. (1844). Vestiges of the natural history of creation. London: John Churchill.

Darwin, C. (1859). On the origin of species. London: John Murray.

Darwin, C. (1871). The descent of man. London: John Murray.

Dewey, E. (1935). Behavior Development in Infants: A Survey of the Literature on Prenatal and Postnatal Activity 1920-1934. New York: Columbia Univ. Press.

Elsner, R, \& Gooden, B. (1983). Diving and Asphyxia: A Comparative Study of Animals and Man. Cambridge: Cambridge Univ. Press.

Evans, N, \& lyer, P. (1994). Incompetence of the foramen ovale in preterm infants supported by mechanical ventilation. Journal of Pediatrics, 125(5), 786-792.

Freitas, R, Gómez-Marin, C, Wilson, JM, Casares, F, \& Gomez-Skarmeta, JL. (2012). Hoxd13 contribution to the evolution of vertebrate appendages. Developmental Cell, 23(6), 1219-1229.

Fugelseth, D, Lindemann, R, Liestøl, K, Kiserud, T, \& Langslet, A. (1998). Postnatal closure of ductus venosus in preterm infants $\leq 32$ weeks. An ultrasonographic study. Early Human Development, 53(2), 163-169.

Gould, SJ. (1977). Ontogeny and phylogeny. Cambridge, MA: Belknap (Harvard Univ.) Press.

Gould, SJ. (1983). Hen's teeth and horse's toes: Further reflections on natural history. New York: Norton.

Hagen, PT, Scholz, DG, \& Edwards, WD. (1984). Incidence and size of patent foramen ovale during the first 10 decades of life: an autopsy study of 965 normal hearts. Mayo Clinic Proceedings, 59(1), 17-20.

Irvine, L. (2004). If You Tame Me: Understanding Our Connection With Animals. Philadelphia: Temple Univ. Press.

Jacob, F. (1977). Evolution and tinkering. Science, 196, 1161-1166.

Janzen, DH, \& Martin, PS. (1982). Neotropical anachronisms: the fruits the gomphotheres ate. Science, 215, 19-27.

Knobloch, IW. (1951). Are there vestigial structures in plants? Science, 113, 465. 
Lafortune, M, Constantin, A, Breton, G, Legare, AG, \& Lavoie, P. (1985). The recanalized umbilical vein in portal hypertension: a myth. American Journal of Roentgenology, 174(5), 1465-1466.

Mayr, E. (1974). Teleological and teleonomic: A new analysis. Boston Studies in the Philosophy of Science, 14(1), 91-117

Muller, GB. (2002). Vestigial organs and structures. In M. Pagel (Ed.), Encyclopedia of Evolution (pp. 1131-1133). New York: Oxford Univ. Press.

Osterauer, R, Marschner, L, Betz, O, Gerberding, M, Sawasdee, B, Cloetens, P, Haus, N, Sures, B, Triebskorn, R, Köhler, H-R. (2010). Turning snails into slugs: induced body plan changes and formation of an internal shell. Evolution \& Development, 12(5), 474-483.

Owen, R. (1841). Notes on the dissection of a Nubian giraffe. Transactions of the Zoological Society of London, 1841, 217-248.

Sadler, TW. (2009). Langman's medical embryology 11e. Philadelphia: Williams \& Wilkins.

Scadding, SR. (1981). Do vestigial organs provide evidence for evolution? Evolutionary Theory, 5, 173-176.

Secord, J. (2001). Victorian sensation: The extraordinary publication, reception, and secret authorship of Vestiges of the Natural History of Creation. Chicago: Univ. of Chicago Press

Sellers, RM. (1995). Wing-spreading behavior of the cormorant Phalacrocorax carbo. Ardea, 83, 27-36

Shubin, N. (2008). Your inner fish: a journey into the 3.5-billion-year history of the human body. New York: Pantheon.

Straus, C, Vasilakos, K, Wilson, RJA, Oshima, T, Zelter, M, Derenne, J-P, Similowski, T, Whitelaw, WA. (2003). A phylogenetic hypothesis for the origin of hiccough. BioEssays, 25(2), 182-188

Van Valen, L. (1973). Festschrift. Science, 180, 488.

Wiedersheim, R. (1893). The structure of man: an index to his past history $2 e$ (trans. H Bernard and M Bernard). London: Macmillan.

Williams, GC. (1997). The pony fish's glow and other clues to plan and purpose in nature. New York: Basic Books.

doi:10.1186/s12052-014-0012-5

Cite this article as: Werth: Vestiges of the natural history of

development: historical holdovers reveal the dynamic interaction

between ontogeny and phylogeny. Evolution: Education and Outreach

2014 7:12.

\section{Submit your manuscript to a SpringerOpen ${ }^{\circ}$ journal and benefit from:}

- Convenient online submission

- Rigorous peer review

- Immediate publication on acceptance

- Open access: articles freely available online

- High visibility within the field

- Retaining the copyright to your article

Submit your next manuscript at $>$ springeropen.com 